\title{
Peritonite difusa devido a úlcera de abomaso perfurada: relato de caso
}

Vinícius Moressi Pinto da Silva, Jeferson Carlos Gandini, Cassiano Tieppo Duque, Thiago Dominik von Schnitzler, Breno Augusto Frederico Ferreira, Camila Agostinho Sartori, Renan Borges Ignácio, Arnaldo Sotero Luz e Souza, Ana Paula Batista Masseno, Fernanda Tamara Neme Mobaid Agudo Romão*

Faculdade de Ensino Superior e Formação Integral (FAEF), Garça, SP, Brasil

*Autor correspondente

e-mail: ftnmaromao@gmail.com

\section{Resumo}

A úlcera de abomaso é a causa mais frequente de hemorragias gastrointestinais em bovinos de todas as idades, podendo acarretar, em algumas vezes, perfuração, resultando em peritonite local aguda dolorosa ou difusa, com morte súbita. As úlceras de abomaso são classificadas em quatro tipos: não perfurantes, não perfurante com perda grave de sangue, perfurantes com peritonite local, perfurante com peritonite difusa. Os sinais clínicos são:mucosas pálidas, taquicardia, queda na produção de leite, melena, dor abdominal moderada marcada por anorexia parcial, diminuição da motilidade ruminal e timpanismo ruminal mediano. 0 tratamento tem como base a correção dos problemas da dieta, redução do estresse, melhora das condições dos problemas doentios simultâneos, assim podendo ser realizado transfusões de sangue e fluidoterapia na úlcera hemorrágica. Uma abordagem racional é a utilização de antiácidos, já que a elevação do pH do conteúdo abomasal pode eliminar a atividade proteolítica da pepsina e reduzir o efeito deletério da acidez da mucosa. Relata-se um caso de um bovino, fêmea, de quatro anos de idade, sem raça definida, que foi atendido no Hospital Veterinário da Faculdade de Ensino Superior e Formação Integral - FAEF, no município de Garça, SP. 0 animal foi submetido ao procedimento cirúrgico de descorna durante aula prátca. 0 procedimento cirúrgico ocorreu com sucesso, entretanto, dois dias depois da cirurgia, observouse apatia, mucosas congestas, taquicardia, taquipnéia, andar arqueado, anorexia, febre e atonia ruminal. Durante o exame específico notou-se dor em região abdominal, sendo resposiva à prova do bastão, porém a paracentese foi improdutiva. 0 hemograma revelou leucopenia por neutropenia, hiperfibrinogenemia e hemoconcentração. Tratamento com ranitidina, florfenicol, fluidoterapia foi realizado durante um dia, pois a vaca morreu no início do segundo dia. Na necropsia durante a avaliação macroscópica no exame externo constatou-se mucosas congestas, aumento de volume abdominal e estado nutricional moderado. 
No exame interno obeservou-se congestão pulmonar acentuada, focos de hemorragia em musculatura em membro anterior esquerdo, fibrina em cavidade abdominal, perfuração em mucosa de abomaso, conteúdo esverdeado em cavidade abdominal em grande quantidade, esplenomegalia, congestão hepática, mucosa gástrica avermelhada, congestão renal difusa acentuada, enterite moderada com conteúdo fecal pastoso e avermelhado. Inicialmente estabeleceu-se a suspeita de úlcera de abomaso, reticuloperitonite traumática. Infelizmente, com o animal vivo não foi possível se chegar a um diagnóstico devido à semelhança dos sinais clínicos entre as doenças, sendo, então, a necropsia essencial para o estabelecimento do diagnóstico. Animais submetidos a cirurgias eletivas podem desenvolver úlceras de abomaso principalmente por estress. As úlceras de abomaso perfuradas causando peritonite difusa são de baixa ocorrência quando comparadas a úlceras de abomaso não perfurantes, e devem ser consideradas em casos de dor abominal, anorexia e atonia ruminal. 